\title{
The diagnostic value of EBV-DNA and EBV-related antibodies detection for nasopharyngeal carcinoma: a meta-analysis
}

Weixing Liu, Gui Chen, Xin Gong, Yingqi Wang, Yaoming Zheng, Xiao Liao, Wenjing Liao, Lijuan Song, Jun Xu and Xiaowen Zhang ${ }^{*}$ (D)

\begin{abstract}
Background: Numerous individual studies have investigated the diagnostic value of EBV-DNA, EA-IgA, VCA-IgA, EBNA1-IgA and Rta-IgG detection for nasopharyngeal carcinoma (NPC), but the conclusions remain controversial. This meta-analysis aimed to determine the value of EBV-DNA, EA-lgA, VCA-lgA, EBNA1-lgA and Rta-lgG detection in the diagnosis of NPC.

Methods: PROSPERO registration number: CRD42019145532. PubMed, EMBASE, Cochrane Library, and Chinese data libraries (Wanfang, CNKI, and CBM) were searched up to January 2019. The pooled sensitivity, specificity, and positive likelihood, negative likelihood, and diagnostic odds ratios were conducted in this meta-analysis. Summary receiver operating characteristic curves evaluated the test-performance global summary. Publication bias was examined by Deek's funnel plot asymmetry test.

Results: Forty-seven studies with 8382 NPC patients (NPC group) and 15,089 individuals without NPC (Control group) were included in this meta-analysis. The sensitivity, specificity, positive likelihood (+LR), negative likelihood (-LR), DOR and AUC of EBV-DNA in diagnosis of NPC were: 0.76 (95\% Cl 0.73-0.77), 0.96 (95\% Cl 0.95-0.97), 14.66 (95\% Cl 9.97-21.55), 0.19 (95\% Cl 0.13-0.28), 84 (95\% Cl 50.45-139.88), 0.96 (SE: 0.001), and 0.55 (95\% Cl 0.54-0.57), 0.96 (95\% Cl 0.96-0.97), 12.91 (95\% Cl 9.55-17.45), 0.35 (95\% Cl 0.29-0.43), 39.57 (95\% Cl 26.44-59.23), 0.94 (SE: 0.002) for the EA-IgA, and 0.85 (95\% Cl 0.84-0.85), 0.89 (95\% Cl 0.88-0.89), 6.73 (95\% Cl5.38-8.43), 0.17 (95\% Cl 0.12-0.23), 43.03 (95\% Cl 31.51-58.76), 0.93 (SE: 0.007) for the VCA-IgA, and 0.86 (95\% Cl 0.85-0.88), 0.87 (95\% Cl 0.88-0.90), 7.55 (95\% Cl 5.79-9.87), 0.16 (95\% Cl 0.13-0.19), 50.95 (95\% Cl 34.35-75.57), 0.94 (SE: 0.008) for the EBNA1-IgA, and 0.70 (95\% Cl 0.69-0.71), 0.94 (95\% Cl 0.94-0.95), 9.84 (95\% Cl 8.40-11.54), 0.25 (95\% Cl 0.21-0.31), 40.59 (95\% Cl 32.09-51.35), 0.95 (SE: 0.005) for the Rta-IgG. The EBV-DNA had larger AUC compared with other EBV-based antibodies $(P<0.05)$, while the difference between EA-IgA, VCA-IgA, EBNA1-IgA and Rta-lgG was not statistically significant $(P>0.05)$.

Conclusions: EBV-DNA, VCA-IgA, EBNA1-IgA and Rta-lgG detection have high accuracy in early diagnosis NPC. In addition, EBV-DNA detection has the higher diagnosis accuracy in NPC. On the other hand, EA-IgA is suitable for the diagnosis but not NPC screening.
\end{abstract}

\footnotetext{
*Correspondence: entxiaowen@163.com

State Key Laboratory of Respiratory Disease, Department

of Otolaryngology-Head and Neck Surgery, First Affiliated Hospital,

Guangzhou Medical University, \#151 Yanjiangxi Road, Guangzhou 510120,

Guangdong, People's Republic of China
}

(c) The Author(s) 2021. This article is licensed under a Creative Commons Attribution 4.0 International License, which permits use, sharing, adaptation, distribution and reproduction in any medium or format, as long as you give appropriate credit to the original author(s) and the source, provide a link to the Creative Commons licence, and indicate if changes were made. The images or other third party material in this article are included in the article's Creative Commons licence, unless indicated otherwise in a credit line to the material. If material is not included in the article's Creative Commons licence and your intended use is not permitted by statutory regulation or exceeds the permitted use, you will need to obtain permission directly from the copyright holder. To view a copy of this licence, visit http://creativeco mmons.org/licenses/by/4.0/. The Creative Commons Public Domain Dedication waiver (http://creativecommons.org/publicdomain/ zero/1.0/) applies to the data made available in this article, unless otherwise stated in a credit line to the data. 
Keywords: Epstein-Barr virus, Nasopharyngeal carcinoma, EBV-DNA, EA-IgA, VCA-IgA, EBNA1-IgA, Rta-lgG, Diagnosis, Meta-analysis

\section{Background}

Nasopharyngeal carcinoma (NPC) is the most common malignant tumor in head and neck surgery and it is highly prevalent in southern China and Southeast Asia [1]. Unfortunately, early-stage patients with NPC are asymptomatic. More than $70 \%$ newly diagnosed NPC are local-advanced or distant metastasis, and the extent of NPC at diagnosis is the most important factor affecting survival rate [2]. Despite radiotherapy and chemoradiotherapy in widespread use as the primary treatment for NPC, the overall prognosis remains poor [3]. Therefore, the use of ideal NPC early diagnosis markers is crucial. Clinical information, laboratory exams and biomedical informatics are significance component in cancer patients [4]. NPC is related to Epstein-Barr virus (EBV) infection which can promote the development of NPC [5]. The detection of specific Epstein-Barr virus DNA and antibodies are important means for the early diagnosis of NPC [6]. In addition, EBV-based antibodies detection has the advantages of rapid, convenient, and low cost. Numerous individual studies have investigated the diagnostic value of EBV-DNA, EA-IgA, VCA-IgA, EBNA1-IgA and Rta-IgG detection for nasopharyngeal carcinoma, but variable sensitivities and specificities were reported. Currently, there is no consensus which is a better test for early diagnosis of NPC. This metaanalysis aimed to determine the value of EBV-DNA, EAIgA, VCA-IgA, EBNA1-IgA and Rta-IgG detection in the diagnosis of NPC and to provide an important basis for NPC screening and early diagnosis. This meta-analysis followed the PRISMA Diagnostic Test Accuracy reporting guidelines [7].

\section{Methods}

PROSPERO registration number: CRD42019145532.

\section{Data sources and literature search strategy}

Literature review was separately conducted by two investigators that queried online databases, including PubMed, EMBASE, Cochrane Library, and Chinese data libraries (WanFang, CNKI, and CBM), and the search concluded in January 2019, using the following keywords: nasopharyngeal carcinoma, Epstein-Barr virus, capsid antigen-IgA, early antigen antibody, nuclear antigen antibody, BRLF1 transcription activator IgG, EBV-DNA, EAIgA, VCA-IgA, EBNA1-IgA and Rta-IgG.

\section{Study selection \\ Inclusion criteria}

1. Studies that assessed the performance of EBV-DNA, EA-IgA, VCA-IgA, EBNA1-IgA and Rta-IgG detection for untreated NPC identification;

2. All patients included in the study were diagnosed using a reference test (such as needle biopsy or postoperative tissue specimens with pathological confirmation);

3. Studies that used a pre-specified threshold;

4. Studies that clearly stated the number of true positive, false positive, false negative, and true negative results in the diagnosis of NPC or these values could be calculated from the data;

5. Studies that provided a clear definition of the control sources (healthy individual or non-NPC patients);

6. In cases of multiple reports describing the same population, the most recent or most complete report was selected.

\section{Exclusion criteria}

1. Reported results were insufficient for construction of the $2 \times 2$ table;

2. Studies that failed to clearly define the control types;

3. The NPC group contained other tumors;

4. Basic research, review articles, comments, letters, case reports, abstracts in conference, responding letters and experimental animal studies.

\section{Study quality assessment and data extraction}

Study quality assessment was conducted using the diagnostic accuracy (QUADAS) II checklist [8]. Studies considered of high quality were eligible for this metaanalysis. Data on study characteristics, the first author, year of publication, country of origin, article language, sample size, control sources (healthy individuals or nonNPC patients), detection method, sample types and cutoff value were extracted from the selected studies by one author and checked by another author. If agreement cannot be reached, a third reviewer will be consulted. Any disagreements were discussed until consensus was reached. 


\section{Statistical analysis}

Standard methods recommended for meta-analyses of diagnostic test evaluations were used to perform this meta-analysis [9]. Review Manager version 5.3, MetaDiSc statistical software version 1.4 and Stata version 14.0 (STATA Corporation, College Station, TX, USA) were used in this meta-analysis. The Cochrane $Q$ test and inconsistency index $\left(I^{2}\right)$ were used to estimate the heterogeneity within studies [10]. Heterogeneity was considered statistically significant when $P<0.05$ or $I^{2}>50 \%$. If statistically significant heterogeneity existed, metaanalysis was performed using the random effects model, otherwise, a fixed effect model was used.

The accuracy indexes of EBV-DNA, EA-IgA, VCA-IgA, EBNA1-IgA and Rta-IgG was pooled by meta-analysis, such as sensitivity, specificity, positive likelihood ratio (PLR), negative likelihood ratio (NLR), diagnostic odds ratio (DOR) and AUC. The likelihood ratios (PLR and NLR) are clinically meaningful for the measurement of diagnostic accuracy; PLR $>10$ and NLR $<0.1$ are considered high [11]. The DOR is a single indicator of test accuracy that combines the data from sensitivity and specificity into a single metric. The summary receiver operating characteristic (SROC) curve was used to evaluate the global summary of test performance.

Sensitivity analyses were performed to explore the sources of heterogeneity of the included studies by removing each included study consecutively. The heterogeneity was investigated by meta-regression according to different covariates, including publication year (Year $\geq 2011$ or $<2011)$, NPC size $($ NPC $\geq 100$ or NPC $<100$ ), control sources (Control sources from healthy serum or from healthy persons and non-NPC patients), detection method, and article language (English or Chinese). Publication bias was examined by Deek's funnel plot asymmetry test. All $P$ values were two sides and $P<0.05$ was regarded as statistically significant.

\section{Results}

\section{Article search and study quality}

In this meta-analysis, 47 publications on the role of EBV-DNA, EA-IgA, VCA-IgA, EBNA1-IgA and Rta-IgG concentrations in the diagnosis of NPC that met the criteria for inclusion were included in the analysis [12-58]. Figure 1 shows a flowchart of the study selection process. The 47 studies included 8382 patients with NPC (NPC group) and 15,089 patients without NPC (Control group). The main features of enrolled studies are summarized in Table 1 . Article quality was judged in terms of the QUADAS II recommendations. The proportions of studies with low, high, or unclear risk of bias and applicability concerns are displayed in Fig. 2.

\section{Heterogeneity investigation}

The inconsistency index (EBV-DNA: $I^{2}=77.5 \%$, $P<0.001$; EA-IgA:77.3\%, $P<0.001$; VCA-IgA: $87.0 \%$, $P<0.001$; EBNA1-IgA:78.9\%, $P<0.001$; Rta-IgG: $60.5 \%$, $P<0.001$ indicated significant heterogeneity among the studies. The result showed that there was no threshold effect in the pooled analysis of EBV-DNA $(P<0.001)$, EA-IgA $(P<0.001)$, VCA-IgA $(P<0.001)$, EBNA1-IgA $(P<0.001)$ and Rta-IgG $(P<0.001)$.

\section{Diagnostic accuracy}

The pooled sensitivity, specificity, PLR, NLR, DOR and AUC for the value of EBV-DNA, EA-IgA, VCA-IgA, EBNA1-IgA and Rta-IgG in the diagnosis of NPC are displayed in Table 2 and the the diagnostic characteristics of included studies are in Tables 3, 4, 5, 6, 7. The EBV-DNA had larger areas under the summary receiver operator curve when compared with EA-IgA, VCAIgA, EBNA1-IgA and Rta-IgG $(P<0.05)$, while EA-IgA, VCA-IgA, EBNA1-IgA and Rta-IgG were no statistically different from each other $(P>0.05)$ in Table 8 . The summary receiver operator curve of EBV-DNA, EAIgA, VCA-IgA, EBNA1-IgA and Rta-IgG detection for NPC were showed in Fig. 3. Additional file 1 showed the Forest plots of sensitivity, specificity, PLR, NLR, DOR for acoustic analysis of EBV-DNA, EA-IgA, VCAIgA, EBNA1-IgA and Rta-IgG.

\section{Sensitivity analysis and meta-regression}

The sensitivity analysis showed that the results were not affected by the exclusion of any individual trial. As meta-regression result indicated that publication year, NPC or control size, control sources, detection method, cutoff value, and article language are not the DOR heterogeneity of EBV-DNA, VCA-IgA, EBNA1-IgA and Rta-IgG, whereas detection method was possible DOR heterogeneity sources for the EA-IgA $(P<0.0095)$.

\section{Publication bias}

Publication bias was judged by Deek's funnel plot asymmetry test, and the statistical results revealed no significant publication bias among studies about EBV-DNA $(P=0.14)$, EA-IgA $(P=0.26)$, EBNA1-IgA $(P=0.56)$ and Rta-IgG $(P=0.16)$, other than VCA-IgA $(P=0.03)$ (Additional file 1).

\section{Discussion}

EBV infection plays a critical role in the progression of nasopharyngeal carcinoma, as body can produce lots of EBV-related antigens at the early stage, which can be used for NPC screening and EBV-DNA, EA-IgA, VCA-IgA and EBNA1-IgA are usually involved [59, 


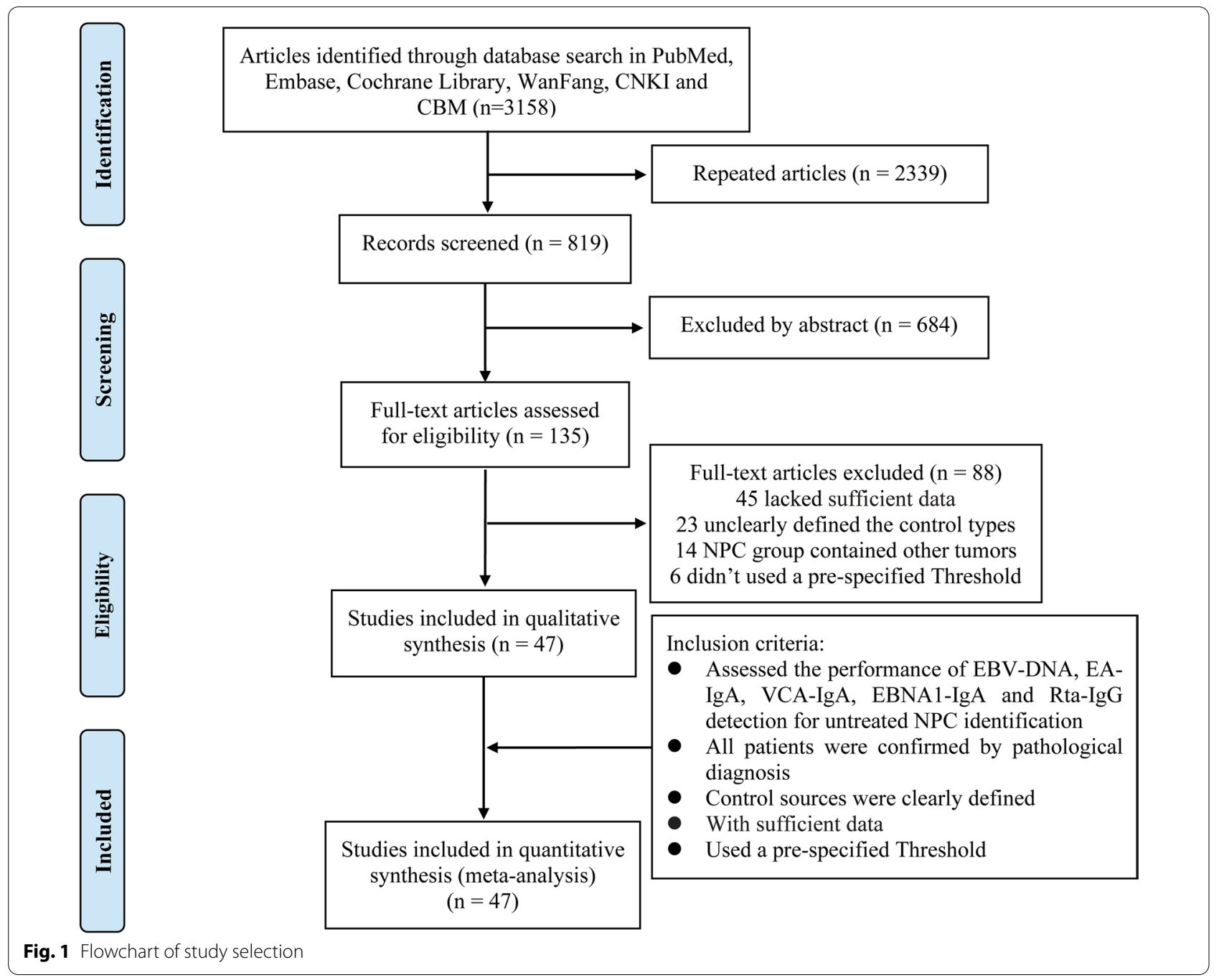

60]. EBV-DNA in circulation may be released from cancer cells during the process of apoptosis or generated from viral replication and different EBV antigens are expressed at different stages of infection [61]. Circulating EBV-DNA has been shown to correlate with the stage of NPC, recurrence rate and screening for NPC [62]. In this study, a meta-analysis was conducted to assess the diagnostic significance of five EBV-based markers for patients with NPC. This study showed that the EBV-DNA, EA-IgA, VCA-IgA, EBNA1-IgA and Rta-IgG detection were effective method for NPC diagnosis.

Previous meta-analyses have been published on the value of some EBV-based markers in the detection of NPC. For the EBV-DNA, Han et al.conducted a metaanalysis based on 18 studies involving 1492 NPC cases and 2461 health controls in Asians, in which the pooled sensitivity and specificity of EBV-DNA detection for NPC were 0.73 (95\% CI 0.71-0.75) and 0.89 (95\% CI 0.88-0.90) [63]. Furthermore, Han et al.found that the accuracy of NPC detection was lower by serum (0.81) than that by plasma (0.86), with SROCs being 0.91 and 0.97 , respectively. The heterogeneity across studies showed significant difference in the Han's study, and Han et al.did not evaluate the threshold effect and publication bias [63]. The Han's study should also perform sensitivity analysis and meta-regression to explore the sources of heterogeneity. Li et al. conducted another important meta-analysis on the diagnosis value of VCA-IgA detection for NPC based on 4671 patients with NPC and 7663 patients without NPC [64], which was correlated with higher pooled sensitivity 0.91 (95\% CI $0.90-0.92)$ and specificity 0.92 (95\% CI $0.92-0.93$ ), with SROC 0.98. But the Li's study existed language bias 
Table 1 Summary data from the 47 included studies

\begin{tabular}{|c|c|c|c|c|c|}
\hline Study ID & Area & Language & NPC & Con & Method \\
\hline Huang [12] & Fu Jian & Chinese & 63 & 51 & $V C A-\lg A, E A-\lg A$ \\
\hline Mai [13] & Guang Dong & English & 66 & 58 & EBV-DNA, VCA-IgA \\
\hline Cheng [14] & Guang Dong & Chinese & 121 & 332 & $V C A-\lg A, E B N A 1-\lg A$ \\
\hline Zhang [15] & Guang Dong & Chinese & 266 & 347 & $V C A-\lg A, E A-\lg A$ \\
\hline Gu [16] & Guang Dong & English & 57 & 58 & EBNA1-IgA \\
\hline Chan [17] & Hong Kong & English & 55 & 163 & EBV-DNA, VCA- IgA, EA-lgA, EBNA1-lgA \\
\hline Shao [18] & Guang Dong & English & 150 & 75 & EBV-DNA \\
\hline Leung [19] & Hong Kong & English & 139 & 178 & EBV-DNA, VCA-IgA \\
\hline $\mathrm{Hu}[20]$ & Guang Dong & Chinese & 85 & 132 & EBNA1-lgA \\
\hline Fachiroh [21] & Indonesia & English & 151 & 254 & EBNA1-lgA \\
\hline Zhu [22] & Guang Xi & Chinese & 274 & 353 & VCA-IgA, Rta-lgG \\
\hline Liang [23] & Guang Dong & Chinese & 195 & 188 & EBNA1-lgA \\
\hline Sun [24] & Hu Nan & Chinese & 68 & 90 & EBV-DNA, VCA-IgA \\
\hline Chang [25] & Tai Wan & English & 156 & 264 & EBV-DNA, VCA-IgA \\
\hline Gu [26] & Guang Dong & English & 135 & 130 & $V C A-\lg A, E B N A 1-\lg A$ \\
\hline Zheng [27] & Guang Xi & Chinese & 211 & 413 & Rta-lgG \\
\hline Luo [28] & Guang Dong & Chinese & 160 & 76 & EBV-DNA, VCA- IgA, EA-lgA \\
\hline Jiang [29] & Guang Dong & Chinese & 81 & 89 & $V C A-\lg A, E A-\lg A, E B N A 1-\lg A$ \\
\hline Deng [30] & Guang Dong & Chinese & 93 & 185 & VCA- IgA, EBNA1-lgA \\
\hline Kong [31] & Shang Dong & Chinese & 56 & 60 & EBV-DNA \\
\hline Sun [32] & Hu Nan & Chinese & 62 & 62 & EBV-DNA, VCA-IgA \\
\hline Liu [33] & Guang Dong & English & 191 & 337 & $V C A-\lg A, E A-\lg A, E B N A 1-\lg A$ \\
\hline Liu [34] & Hu Bei & Chinese & 50 & 50 & EBV-DNA \\
\hline Zhu [35] & Jiang Su & Chinese & 168 & 60 & EBV-DNA, VCA-IgA \\
\hline Wang [36] & Shang Hai & Chinese & 206 & 248 & VCA-lgA, EBNA1-lgA, Rta-lgG \\
\hline Ai [37] & Si Chuan & English & 100 & 60 & VCA-lgA, EBNA1-lgA, Rta-lgG \\
\hline Deng [38] & Guang Dong & Chinese & 124 & 173 & VCA-lgA, EBNA1-lgA \\
\hline Li [39] & Guang Dong & Chinese & 145 & 140 & EBV-DNA \\
\hline Li [40] & Fu Jian & Chinese & 449 & 82 & VCA-IgA, EA-lgA, Rta-lgG \\
\hline Luo [41] & Guang Zhou & Chinese & 131 & 200 & EBV-DNA, VCA-lgA, EA-lgA, Rta-lgG \\
\hline Yan [42] & Bei Jing & Chinese & 50 & 51 & $V C A-\lg A, E A-\lg A$ \\
\hline Tang [43] & Guang Xi & Chinese & 150 & 150 & Rta-lgG \\
\hline Cai [44] & Guang Xi & English & 211 & 413 & VCA-IgA, EA-lgA, EBNA1-lgA, Rta-lgG \\
\hline Peng [45] & Guang Dong & English & 310 & 218 & $V C A-\lg A$ \\
\hline Xu [46] & Guang Dong & Chinese & 75 & 100 & VCA-IgA, Rta-lgG \\
\hline Cui [47] & Shan Xi & English & 64 & 120 & VCA-lgA, EA-IgA, Rta-lgG \\
\hline Ye [48] & Fu Jian & Chinese & 160 & 299 & EBV-DNA, VCA-lgA, EA-lgA, Rta-lgG \\
\hline Li [49] & Guang Dong & English & 208 & 198 & EBV-DNA, VCA-lgA \\
\hline Yu [50] & Guang Dong & Chinese & 152 & 675 & EBV-DNA, VCA-IgA, EBNA1-IgA \\
\hline Li [51] & Shang Hai & English & 56 & 90 & EBV-DNA, VCA-lgA, Rta-lgG, EA-lgG \\
\hline Zhao [52] & Guang Xi & Chinese & 89 & 120 & Rta-lgG \\
\hline Gu [53] & Guang Dong & Chinese & 60 & 60 & VCA- IgA, EBNA1-lgA \\
\hline Guo [54] & Fu Jian & Chinese & 2155 & 6957 & VCA-lgA, EA-lgA, Rta-lgG \\
\hline Rui [55] & Guang Dong & English & 200 & 200 & VCA-lgA, EBNA1-IgA \\
\hline Zhao [56] & Guang Dong & Chinese & 80 & 80 & EBV-DNA \\
\hline Yi [57] & Fu Jian & Chinese & 96 & 250 & VCA-lgA, EA-lgA, Rta-lgG \\
\hline Zhang [58] & Hu Nan & Chinese & 58 & 200 & VCA-IgA, EA-lgA, Rta-lgG \\
\hline
\end{tabular}




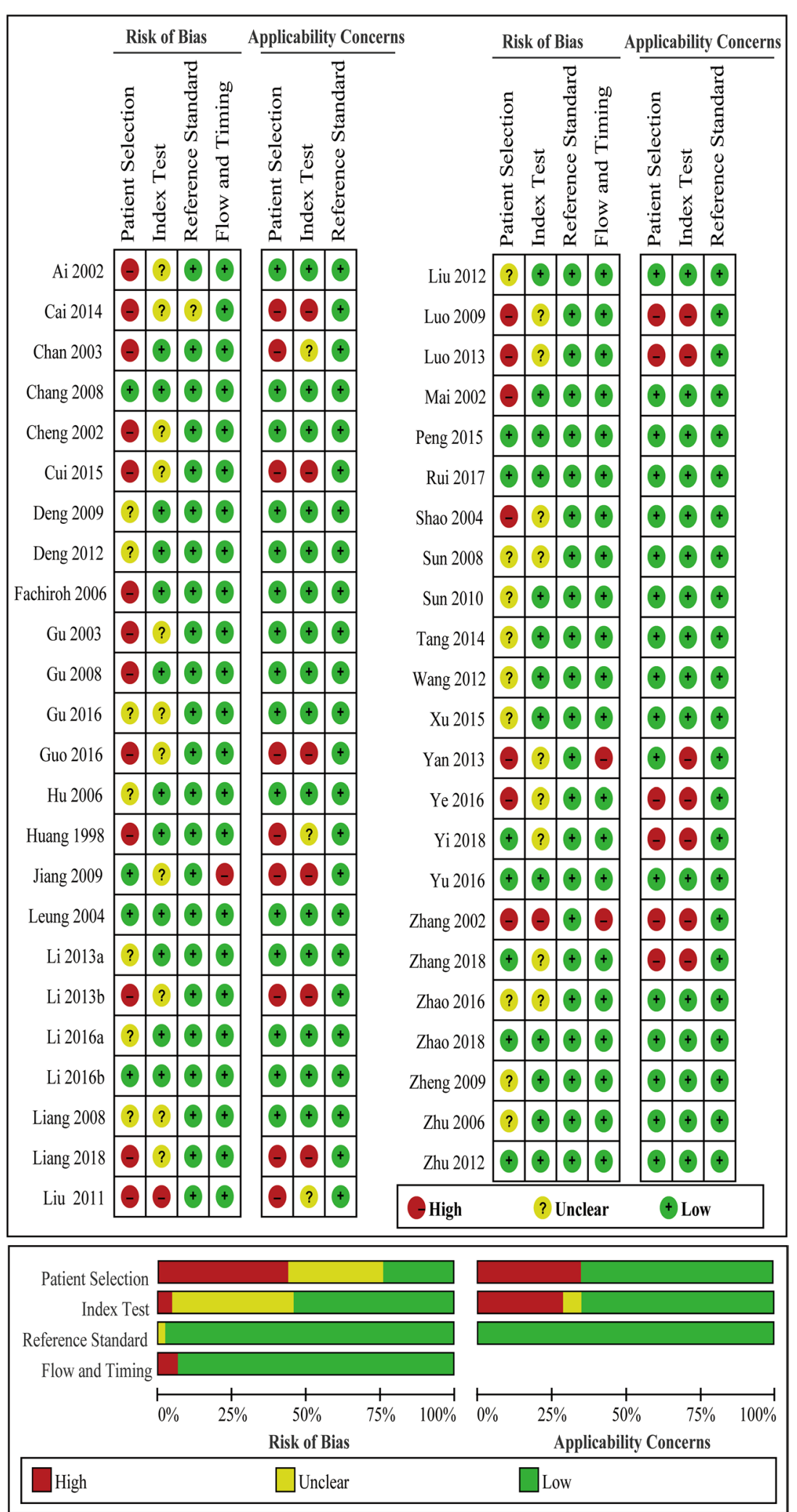

Fig. 2 Assessment of the reporting quality of the included studies using the QUADAS II checklist 
Table 2 The pooled result of EBV-DNA, EA-IgA, VCA-IgA, EBNA1-lgA and Rta-lgG in the diagnosis of NPC

\begin{tabular}{|c|c|c|c|c|c|c|}
\hline Method & $\begin{array}{l}\text { Pooled sensitivity } \\
(95 \% \mathrm{Cl})\end{array}$ & $\begin{array}{l}\text { Pooled specificity } \\
(95 \% \mathrm{Cl})\end{array}$ & Pooled PLR (95\% Cl) & Pooled NLR (95\% Cl) & Pooled DOR (95\% Cl) & $A \cup C$ (SE) \\
\hline \multirow[t]{2}{*}{ EBV-DNA } & 0.76 & 0.96 & 14.66 & 0.19 & 84.00 & 0.96 \\
\hline & $0.73-0.77$ & $0.95-0.97$ & $9.97-21.55$ & $0.13-0.28$ & $50.45-139.88$ & 0.0011 \\
\hline \multirow[t]{2}{*}{$E A-\lg A$} & 0.55 & 0.96 & 12.91 & 0.35 & 39.57 & 0.94 \\
\hline & $0.54-0.57$ & $0.96-0.97$ & $9.55-17.45$ & $0.29-0.43$ & $26.44-59.23$ & 0.00274 \\
\hline \multirow[t]{2}{*}{ VCA-IgA } & 0.85 & 0.89 & 6.73 & 0.17 & 43.03 & 0.93 \\
\hline & $0.84-0.85$ & $0.88-0.89$ & $5.38-8.43$ & $0.12-0.23$ & $31.51-58.76$ & 0.0076 \\
\hline \multirow[t]{2}{*}{ EBNA1-IgA } & 0.86 & 0.87 & 7.55 & 0.16 & 50.95 & 0.94 \\
\hline & $0.85-0.88$ & $0.88-0.90$ & $5.79-9.87$ & $0.13-0.19$ & $34.35-75.57$ & 0.0089 \\
\hline \multirow[t]{2}{*}{ Rta-lgG } & 0.70 & 0.94 & 9.84 & 0.25 & 40.59 & 0.95 \\
\hline & $0.69-0.7149$ & $0.94-0.95$ & $8.40-11.54$ & $0.21-0.31$ & $32.09-51.35$ & 0.0052 \\
\hline
\end{tabular}

Table 3 The diagnostic characteristics of included studies on EBV-DNA

\begin{tabular}{lrrrrrr}
\hline Study ID & TP & FP & FN & TN & Sensitive (95\% Cl) & Specificity (95\% Cl) \\
\hline Mai [13] & 56 & 6 & 10 & 52 & $0.85(0.74-0.93)$ & $0.90(0.79-0.96)$ \\
Chan [17] & 31 & 3 & 24 & 160 & $0.56(0.42-0.70)$ & $0.98(0.95-0.99)$ \\
Shao [18] & 138 & 9 & 12 & 66 & $0.92(0.86-0.95)$ & $0.88(0.78-0.94)$ \\
Leung [19] & 132 & 4 & 7 & 174 & $0.95(0.90-0.98)$ & $0.98(0.94-0.99)$ \\
Sun [24] & 65 & 6 & 3 & 84 & $0.96(0.88-0.99)$ & $0.93(0.86-0.98)$ \\
Chang [25] & 127 & 9 & 29 & 255 & $0.81(0.74-0.87)$ & $0.97(0.94-0.98)$ \\
Luo [28] & 110 & 9 & 50 & 67 & $0.69(0.61-0.75)$ & $0.88(0.79-0.94)$ \\
Sun [32] & 59 & 4 & 3 & 58 & $0.95(0.86-0.99)$ & $0.94(0.84-0.98)$ \\
Liu [34] & 46 & 4 & 4 & 46 & $0.92(0.80-0.98)$ & $0.92(0.81-0.98)$ \\
Zhu [35] & 58 & 2 & 110 & 58 & $0.35(0.27-0.42)$ & $0.97(0.89-0.99)$ \\
Li [39] & 136 & 10 & 9 & 130 & $0.94(0.89-0.97)$ & $0.93(0.87-0.97)$ \\
Luo [41] & 85 & 6 & 46 & 194 & $0.65(0.56-0.73)$ & $0.97(0.94-0.99)$ \\
Ye [48] & 94 & 7 & 66 & 292 & $0.59(0.51-0.67)$ & $0.98(0.95-0.99)$ \\
Li [49] & 149 & 10 & 59 & 188 & $0.72(0.65-0.78)$ & $0.95(0.91-0.98)$ \\
Yu [50] & 123 & 3 & 29 & 672 & $0.81(0.74-0.87)$ & $0.99(0.98-0.99)$ \\
Li [51] & 37 & 3 & 19 & 87 & $0.66(0.52-0.78)$ & $0.97(0.91-0.99)$ \\
Zhao [56] & 72 & 16 & 8 & 64 & $0.90(0.81-0.97)$ & $0.80(0.70-0.88)$
\end{tabular}

and publication bias. For the Rta-IgG, Cui et al.pooled 17 studies involving 2658 NPC patients, and the results pointed out that the sensitivity of Rta-IgG for detecting NPC was 90.83 (95\% CI 0.78-0.87), the specificity was 0.92 (95\% CI 0.90-0.93) [65]. Threshold effect, publication bias as well as complicated control types presented in the Cui's study, which may contribute to heterogeneity and affect the accuracy of pooled results. Additionally, previous meta-analyses could not reach a conclusive result as to the most favorable choice for NPC diagnosis.
To our knowledge, this is the first meta-analysis to determine the usefulness of EA-IgA and EBNA1-IgA and compare the accuracy EBV-DNA, EA-IgA, VCAIgA, EBNA1-IgA and Rta-IgA in diagnosis of NPC. In this study, the highest sensitivity was EBNA1-IgA (0.86), and the specificity of EBV-DNA (0.96) and EA-IgA (0.96) were highest. Besides, the sensitivity of EA-IgA (0.55) was lowest, and screening for NPC using only EA-IgA may lead to misdiagnosis, but the specificity was high, which indicated that EA-IgA was suitable for the diagnosis but not screening of NPC. EA-IgA or EBV-DNA detection combined with other 
Table 4 The diagnostic characteristics of included studies on EA-lgA

\begin{tabular}{lrrrrrr}
\hline Study ID & TP & FP & FN & TN & Sensitive (95\% Cl) & Specificity (95\% Cl) \\
\hline Huang [12] & 36 & 1 & 27 & 50 & $0.57(0.44-0.70)$ & $0.98(0.90-1.00)$ \\
Zhang [15] & 239 & 41 & 27 & 306 & $0.90(0.86-0.93)$ & $0.88(0.84-0.91)$ \\
Chan [17] & 40 & 5 & 15 & 158 & $0.73(0.59-0.84)$ & $0.97(0.93-0.99)$ \\
Luo [28] & 120 & 4 & 40 & 72 & $0.75(0.68-0.82)$ & $0.95(0.87-0.99)$ \\
Jiang [29] & 53 & 5 & 28 & 84 & $0.65(0.54-0.76)$ & $0.94(0.87-0.98)$ \\
Liu [33] & 89 & 17 & 102 & 320 & $0.47(0.39-0.54)$ & $0.95(0.92-0.97)$ \\
Luo [41] & 98 & 1 & 33 & 199 & $0.75(0.67-0.82)$ & $0.99(0.97-1.00)$ \\
Li [40] & 210 & 6 & 239 & 76 & $0.47(0.42-0.52)$ & $0.93(0.85-0.97)$ \\
Yan [42] & 16 & 2 & 35 & 48 & $0.31(0.19-0.46)$ & $0.96(0.86-0.99)$ \\
Cai [44] & 188 & 3 & 23 & 200 & $0.89(0.84-0.93)$ & $0.99(0.96-0.99)$ \\
Cui [47] & 46 & 4 & 18 & 116 & $0.72(0.59-0.82)$ & $0.98(0.92-0.99)$ \\
Ye [48] & 94 & 12 & 66 & 287 & $0.59(0.51-0.67)$ & $0.96(0.93-0.98)$ \\
Guo [54] & 1004 & 213 & 1151 & 6744 & $0.47(0.45-0.49)$ & $0.97(0.97-0.97)$ \\
Yi [57] & 47 & 10 & 49 & 240 & $0.49(0.39-0.59)$ & $0.96(0.93-0.98)$ \\
Zhang [58] & 42 & 23 & 16 & 177 & $0.72(0.59-0.83)$ & $0.89(0.83-0.93)$ \\
\hline
\end{tabular}

indicators may also improve the sensitivity and specificity for the serological diagnosis of NPC [44, 51]. The likelihood ratios (PLR and NLR) calculated from the sensitivity and specificity indicate the discriminatory properties of negative and positive test results. The pooled PLR of EBV-DNA, VCA-IgA and EA-IgA were above 5 and NLR below 0.2, which given strong diagnosis evidence especially for EBV-DNA and EAIgA with PLR above 10 [11]. Furthermore, a summary receiver operating characteristic (SROC) curve was also conducted to describe the relationship between sensitivity and specificity. AUC can summarize the inherent capacity of a test to discriminate the participant with disease from those without it $[66,67]$. The AUC of EBV-DNA and other antibodies were more than $90 \%$, indicating a very high level of overall accuracy. The EBV-DNA (AUC $=0.96$ ) had slightly larger AUC compared with EA-IgA, VCA-IgA, EBNA1-IgA and Rta-IgG $(P<0.05)$. Additionally, the pooled DOR of EBV-DNA (84.00) that differed 33.05-44.43 was higher than other EBV-based antibodies. These results indicated that EBV-DNA detection had higher accuracy in diagnosis of NPC. In addition, a meta-analysis included 8128 NPC cases showed that pre-EBV-DNA levels can also be a prognostic indictor for patients with NPC [68]. A recent prospective screening study involving 20,174 participants showed that plasma EBV-DNA detection was useful in screening for early asymptomatic nasopharyngeal carcinoma screening, with $97.1 \%$ sensitivity and $98.6 \%$ specificity [2]. But only 309/1112 had detectable Epstein-Barr virus DNA in plasma at baseline and at follow-up, and 35 patients had confirmed nasopharyngeal carcinoma. In Nicholls' study [15], seventy-eight NPC patients (15.1\%) were plasma EBV-DNA negative who had similar 5-year overall survival and cancer-specific survival to those EBV-DNA positive counterparts by stage. If only plasma EBV-DNA was used as the population screening tool, $60.0 \%, 23.0 \%, 14.5 \%$ and $5.0 \%$ of stage I, II, III and IVA NPC may be missed. The golden standard for cancer prognosis is pathological examination following the complicated and painful procedures of biopsy, which may not be feasible by some patients [69]. In addition, endoscopic, computed tomography (CT) and Magnetic resonance imaging (MRI) has been the imaging modality of choice for cancer diagnosis and staging $[70,71]$. In practice, due to the current limitations of a single serum index, multiple assays (nasal endoscopy, $\mathrm{CT}$ and MRI) and biopsies [70, 72], it is still necessary develop methods to increase NPC early diagnostic rate.

Several strengths of present meta-analysis should be highlighted. This study compered five EBV-related diagnostic markers for NPC with comprehensive calculations of their diagnostic performance, shedding light on the value of these tests in clinical settings. In the context of current availability of studies on EBV-DNA and immunoglobin antibody tests in the literature, this meta-analysis covers a large sample size pooled from rigorously included studies, and 
Table 5 The diagnostic characteristics of included studies on VCA-IgA

\begin{tabular}{|c|c|c|c|c|c|c|}
\hline Study ID & $\mathrm{TP}$ & FP & FN & $\mathrm{TN}$ & Sensitive $(95 \% \mathrm{Cl})$ & Specificity (95\% Cl) \\
\hline Huang [12] & 62 & 6 & 1 & 55 & $0.98(0.92-1.00)$ & $0.90(0.80-0.96)$ \\
\hline Mai [13] & 53 & 6 & 13 & 52 & $0.80(0.69-0.89)$ & $0.90(0.79-0.96)$ \\
\hline Cheng [14] & 112 & 43 & 9 & 289 & $0.93(0.86-0.97)$ & $0.87(0.83-0.91)$ \\
\hline Zhang [15] & 241 & 19 & 25 & 328 & $0.97(0.86-0.94)$ & $0.95(0.91-0.97)$ \\
\hline Chan [17] & 51 & 60 & 4 & 98 & $0.94(0.82-0.98)$ & $0.62(0.54-0.70)$ \\
\hline Leung [19] & 112 & 8 & 27 & 170 & $0.87(0.73-0.87)$ & $0.96(0.91-0.98)$ \\
\hline Zhu [22] & 248 & 53 & 26 & 300 & $0.91(0.86-0.94)$ & $0.85(0.80-0.89)$ \\
\hline Sun [24] & 63 & 45 & 5 & 45 & $0.93(0.84-0.98)$ & $0.50(0.39-0.61)$ \\
\hline Chang [25] & 134 & 36 & 22 & 228 & $0.86(0.79-0.91)$ & $0.86(0.82-0.90)$ \\
\hline Gu [26] & 124 & 37 & 15 & 93 & $0.89(0.83-0.94)$ & $0.71(0.63-0.79)$ \\
\hline Luo [28] & 144 & 8 & 16 & 68 & $0.90(0.84-0.94)$ & $0.90(0.80-0.95)$ \\
\hline Jiang [29] & 77 & 9 & 4 & 80 & $0.95(0.88-0.99)$ & $0.90(0.81-0.95)$ \\
\hline Deng [30] & 81 & 12 & 12 & 173 & $0.87(0.79-0.93)$ & $0.94(0.89-0.97)$ \\
\hline Sun [32] & 63 & 45 & 5 & 45 & $0.93(0.84-0.98)$ & $0.50(0.39-0.61)$ \\
\hline Liu [33] & 174 & 65 & 17 & 272 & $0.91(0.86-0.95)$ & $0.81(0.76-0.85)$ \\
\hline Zhu [35] & 105 & 2 & 63 & 28 & $0.63(0.55-0.70)$ & $0.93(0.78-0.99)$ \\
\hline Wang [36] & 179 & 11 & 27 & 237 & $0.87(0.81-0.91)$ & $0.96(0.92-0.98)$ \\
\hline Ai [37] & 43 & 4 & 57 & 56 & $0.43(0.33-0.53)$ & $0.93(0.84-0.98)$ \\
\hline Deng [38] & 94 & 15 & 30 & 158 & $0.76(0.67-0.83)$ & $0.91(0.86-0.95)$ \\
\hline Luo [41] & 122 & 26 & 9 & 305 & $0.93(0.87-0.97)$ & $0.92(0.89-0.95)$ \\
\hline Li [40] & 397 & 18 & 52 & 64 & $0.88(0.85-0.91)$ & $0.78(0.68-0.86)$ \\
\hline Yan [42] & 39 & 3 & 12 & 47 & $0.77(0.63-0.87)$ & $0.94(0.84-0.99)$ \\
\hline Cai [44] & 207 & 35 & 14 & 168 & $0.94(0.90-0.97)$ & $0.83(0.77-0.88)$ \\
\hline Peng [45] & 163 & 16 & 147 & 202 & $0.53(0.47-0.58)$ & $0.93(0.88-0.96)$ \\
\hline Xu [46] & 67 & 16 & 8 & 84 & $0.89(0.80-0.95)$ & $0.84(0.75-0.91)$ \\
\hline Cui [47] & 51 & 6 & 13 & 114 & $0.80(0.68-0.89)$ & $0.95(0.89-0.98)$ \\
\hline Ye [48] & 151 & 49 & 9 & 250 & $0.94(0.90-0.97)$ & $0.84(0.79-0.88)$ \\
\hline Li [49] & 176 & 13 & 32 & 185 & $0.85(0.79-0.89)$ & $0.93(0.89-0.96)$ \\
\hline Yu [50] & 68 & 56 & 84 & 619 & $0.45(0.37-0.53)$ & $0.91(0.89-0.93)$ \\
\hline Li [51] & 44 & 8 & 12 & 81 & $0.79(0.67-0.88)$ & $0.91(0.83-0.96)$ \\
\hline Gu [53] & 20 & 11 & 40 & 49 & $0.33(0.22-0.47)$ & $0.82(0.70-0.91)$ \\
\hline Guo [54] & 1937 & 710 & 218 & 6247 & $0.90(0.89-0.91)$ & $0.90(0.89-0.91)$ \\
\hline Rui [55] & 176 & 29 & 24 & 171 & $0.88(0.83-0.92)$ & $0.86(0.80-0.90)$ \\
\hline Yi [57] & 85 & 28 & 11 & 222 & $0.89(0.80-0.94)$ & $0.89(0.84-0.92)$ \\
\hline Zhang [58] & 36 & 20 & 12 & 180 & $0.75(0.60-0.86)$ & $0.90(0.85-0.94)$ \\
\hline
\end{tabular}

the results were stable. However, this meta-analysis should be interpreted with caution due to certain limitations. First, there was large heterogeneity among the included studies with differences in characteristics of the study and participants. The inability to obtain raw data on patient age and gender may have led to the heterogeneity and hindered a more detailed analysis. Second, most of the included populations were Chinese, which could lead to population selection bias and should not allow for generalization to other ethnicity groups, rendering further research needed. Third, technical methods for testing of EBV-related markers vary across different studies, including the inconsistent cut-off values and different antigen sets used despite of a same generic name. Use of enzymelinked immunosorbent assay or immunofluorescence assay may have contributed to the different results [73]. Finally, most of the studies included NPC cases and controls in a single institution or from a same geographic region, which could have influenced the results of the study. Therefore, a larger, prospective, 
Table 6 The diagnostic characteristics of included studies on EBNA1-IgA

\begin{tabular}{lrrrrrr}
\hline Study ID & TP & FP & FN & TN & Sensitive (95\% Cl) & Specificity (95\% CI) \\
\hline Cheng [14] & 103 & 50 & 18 & 285 & $0.85(0.78-0.91)$ & $0.85(0.80-0.89)$ \\
Gu [16] & 52 & 7 & 6 & 51 & $0.90(0.79-0.96)$ & $0.88(0.78-0.95)$ \\
Chan [17] & 46 & 22 & 9 & 141 & $0.84(0.71-0.92)$ & $0.87(0.80-0.91)$ \\
Hu [20] & 69 & 25 & 16 & 107 & $0.81(0.71-0.89)$ & $0.81(0.73-0.87)$ \\
Fachiroh [21] & 134 & 51 & 17 & 203 & $0.89(0.83-0.93)$ & $0.80(0.75-0.85)$ \\
Liang [23] & 166 & 28 & 29 & 160 & $0.85(0.79-0.90)$ & $0.85(0.79-0.90)$ \\
Gu [26] & 108 & 26 & 27 & 104 & $0.80(0.72-0.86)$ & $0.80(0.72-0.87)$ \\
Deng [30] & 83 & 10 & 10 & 175 & $0.89(0.81-0.95)$ & $0.95(0.90-0.97)$ \\
Liu [33] & 177 & 48 & 14 & 289 & $0.93(0.88-0.96)$ & $0.86(0.81-0.89)$ \\
Wang [36] & 94 & 11 & 12 & 238 & $0.89(0.81-0.94)$ & $0.96(0.92-0.98)$ \\
Ai [37] & 85 & 12 & 15 & 48 & $0.85(0.77-0.91)$ & $0.80(0.68-0.89)$ \\
Deng [38] & 137 & 9 & 31 & 77 & $0.82(0.75-0.87)$ & $0.90(0.81-0.95)$ \\
Cai [44] & 184 & 32 & 27 & 171 & $0.87(0.82-0.91)$ & $0.84(0.79-0.89)$ \\
Yu [50] & 120 & 21 & 32 & 654 & $0.79(0.72-0.85)$ & $0.97(0.95-0.98)$ \\
Gu [53] & 53 & 2 & 7 & 58 & $0.88(0.77-0.95)$ & $0.97(0.89-1.00)$ \\
Rui [55] & 188 & 15 & 12 & 185 & $0.94(0.90-0.97)$ & $0.93(0.88-0.96)$ \\
\hline
\end{tabular}

Table 7 The diagnostic characteristics of included studies on Rta-lgG

\begin{tabular}{lrrrrrr}
\hline Study ID & TP & FP & FN & TN & Sensitive (95\% Cl) & Specificity (95\% Cl) \\
\hline Zhu [22] & 225 & 29 & 49 & 324 & $0.82(0.77-0.87)$ & $0.92(0.88-0.94)$ \\
Zheng [27] & 191 & 41 & 20 & 372 & $0.91(0.86-0.94)$ & $0.90(0.87-0.93)$ \\
Wang [36] & 132 & 21 & 74 & 228 & $0.64(0.57-0.71)$ & $0.92(0.87-0.95)$ \\
Ai [37] & 77 & 5 & 23 & 55 & $0.77(0.68-0.85)$ & $0.92(0.82-0.97)$ \\
Luo [41] & 102 & 15 & 29 & 185 & $0.78(0.70-0.85)$ & $0.93(0.88-0.96)$ \\
Li [40] & 335 & 6 & 114 & 76 & $0.75(0.70-0.79)$ & $0.93(0.85-0.97)$ \\
Tang [43] & 134 & 16 & 17 & 133 & $0.89(0.83-0.93)$ & $0.89(0.83-0.94)$ \\
Cai [44] & 191 & 30 & 20 & 173 & $0.91(0.86-0.94)$ & $0.85(0.80-0.90)$ \\
Xu [46] & 61 & 7 & 14 & 93 & $0.81(0.71-0.89)$ & $0.93(0.86-0.97)$ \\
Cui [47] & 48 & 4 & 16 & 116 & $0.75(0.63-0.85)$ & $0.97(0.92-0.99)$ \\
Ye [48] & 122 & 17 & 38 & 282 & $0.76(0.69-0.83)$ & $0.94(0.91-0.97)$ \\
Li [51] & 43 & 7 & 13 & 83 & $0.77(0.64-0.87)$ & $0.92(0.85-0.97)$ \\
Zhao [52] & 67 & 6 & 21 & 124 & $0.76(0.66-0.85)$ & $0.95(0.90-0.98)$ \\
Guo [54] & 1363 & 352 & 792 & 6605 & $0.63(0.61-0.65)$ & $0.95(0.94-0.95)$ \\
Yi [57] & 63 & 12 & 33 & 238 & $0.66(0.55-0.75)$ & $0.95(0.92-0.98)$ \\
Zhang [58] & 42 & 23 & 16 & 177 & $0.72(0.59-0.83)$ & $0.89(0.83-0.93)$ \\
\hline
\end{tabular}

randomized and multicentered clinical trial should been done to evaluate the diagnostic value of EBVbased tools in the diagnosis of NPC.

\section{Conclusions}

Notwithstanding heterogeneity of currently available data, the studies included in our analysis are of a large sample size and high-quality, thus providing a considerable power. EBV-DNA, VCA-IgA, EBNA1-IgA and Rta-IgG detection have high accuracy in early diagnosis NPC and can improve the effectiveness of screening. In addition, EBV-DNA detection has the higher diagnosis accuracy in NPC. On the other hand, EA-IgA is suitable 
Table 8 The $Z$ test of EBV-DNA, EA-IgA, VCA-lgA, EBNA1-IgA and Rta-lgG in the diagnosis of NPC

\begin{tabular}{lcc}
\hline Method & $Z$ & $P$ \\
\hline EBV-DNA VS VCA-IgA & 3.61 & $<0.001$ \\
EBV-DNA VS EA-IgA & 6.52 & $<0.001$ \\
EBV-DNA VS EBNA1-IgA & 2.98 & 0.003 \\
EBV-DNA VS Rta-lgG & 2.69 & 0.007 \\
VCA-IgA VS EA-lgA & -1.05 & 0.293 \\
VCA-IgA VS EBNA1-IgA & -0.09 & 0.932 \\
VCA-IgA VS Rta-IgG & -1.46 & 0.146 \\
EA-IgA VS EBNA1-IgA & 0.81 & 0.421 \\
EA-IgA VS Rta-IgG & -0.84 & 0.404 \\
EBNA1-IgA VS Rta-IgG & -1.20 & 0.229 \\
\hline
\end{tabular}

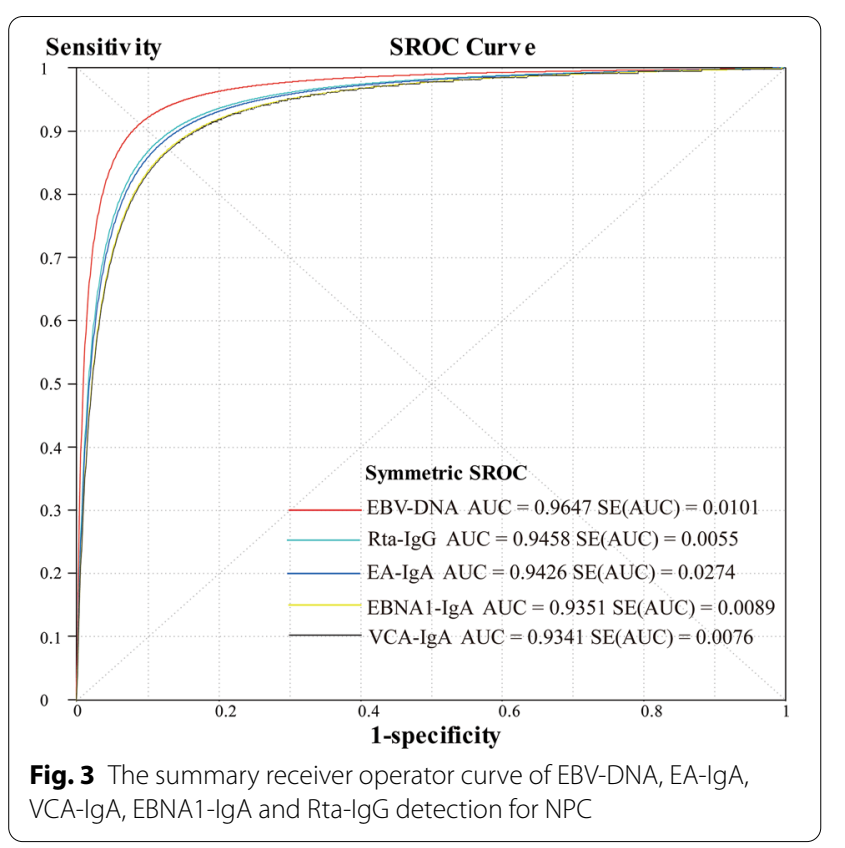

for the diagnosis but not NPC screening. Further welldesigned clinical trials need to be carried out in order to improve early diagnosis rate.

\section{Abbreviations}

NPC: Nasopharyngeal carcinoma; Cl: Confidence interval; PLR: Positive likelihood ratio; NLR: Negative likelihood ratio; DOR: Diagnostic odds ratio; AUC: Area under the Curve; SROC: Summary receiver operating characteristic.

\section{Supplementary Information}

The online version contains supplementary material available at https://doi. org/10.1186/s12935-021-01862-7.

Additional file 1: Forest plots of sensitivity, specificity, PLR, NLR, DOR for acoustic analysis of EBV-DNA, EA-lgA, VCA-IgA, EBNA1-IgA and Rta-lgG, and Funnel plots for publication bias test.

\section{Acknowledgements}

Weixing Liu, Gui Chen and Xin Gong are co-first author. Thank you Professor Wang Xinwang and Zeng Guangqiao for their help on statistical methods and manuscript writing.

\section{Authors' contributions}

Weixing Liu, Gui Chen, Xin Gong and Xiaowen Zhang participated in the design, data acquisition, data analysis, manuscript writing, and Xiaowen Zhang have given final approval of the version to be published. Yingqi Wang, Yaoming Zheng, Xiao Liao, Wenjing Liao, Lijuan Song, and Jun Xu performed data analysis, data acquisition. All authors read and approved the final manuscript.

\section{Funding}

Funding was received from Upper Respiratory Disease Innovation and Transformation Platform Construction Project of Guangdong Provincial and High-level Construction Project of Guangzhou Medical University.

\section{Availability of data and materials}

The datasets used during the current study are available from the corresponding author on reasonable request.

\section{Declarations}

\section{Ethics approval and consent to participate}

Not applicable.

\section{Consent for publication}

No identifying patient details are contained within this manuscript.

\section{Competing interests}

The authors declare no competing interests.

Received: 8 November 2019 Accepted: 2 March 2021

Published online: 10 March 2021

\section{References}

1. Wei KR, Zheng RS, Zhang SW, Liang ZH, Li ZM, Chen WQ. Nasopharyngeal carcinoma incidence and mortality in China, 2013. Chin J Cancer. 2017:36(1):90. https://doi.org/10.1186/s40880-017-0257-9.

2. Chan KCA, Woo JKS, King A, et al. Analysis of plasma epstein-barr virus DNA to screen for nasopharyngeal cancer. N Engl J Med. 2017;377(6):513-22. https://doi.org/10.1056/NEJMoa1701717.

3. Lee AW, Ma BB, Ng WT, Chan AT. Management of nasopharyngeal carcinoma: current practice and future perspective. J Clin Oncol. 2015:33(29):3356-64. https://doi.org/10.1200/JCO.2015.60.9347.

4. Kosvyra A, Maramis C, Chouvarda I. Developing an integrated genomic profile for cancer patients with the use of NGS data. Emerging Sci J. 2019;3:157-67. https://doi.org/10.28991/esj-2019-01178.

5. Lam WKJ, Chan JYK. Recent advances in the management of nasopharyngeal carcinoma. F1000Res. 2018;7:F1000 Faculty Rev-1829. https:/ doi.org/10.12688/f1000research.15066.1.

6. Chen Y, Chan ATC, Le Q, Blanchard P, Sun Y, Ma J. Nasopharyngeal carcinoma. Lancet. 2019;394:64-80. https://doi.org/10.1016/S0140 -6736(19)30956-0.

7. Mclnnes MDF, Moher D, Thombs BD, et al. Preferred reporting items for a systematic review and meta-analysis of diagnostic test accuracy studies: the PRISMA-DTA statement. JAMA. 2018;319(4):388-96. https://doi. org/10.1001/jama.2017.19163.

8. Whiting PF, Rutjes AW, Westwood ME, et al. QUADAS-2: a revised tool for the quality assessment of diagnostic accuracy studies. Ann Intern Med. 2011;155(8):529-36. https://doi.org/10.7326/0003-4819-155-8-20111 0180-00009.

9. Walter Devillé L, Buntinx F, Bouter $L M$, et al. Conducting systematic reviews of diagnostic studies: didactic guidelines. BMC Med Res Methodol. 2002;9(2):1-13. https://doi.org/10.1186/1471-2288-2-9.

10. Jaeschke R, Guyatt GH, Sackett DL. Users' guides to the medical literature III How to use an article about a diagnostic test B What are the results and will they help me in caring for my patients? The Evidence-Based 
Medicine Working Group. JAMA. 1994;271(9):703-7. https://doi. org/10.1001/jama.271.9.703.

11. Deeks JJ. Systematic reviews in health care: Systematic reviews of evaluations of diagnostic and screening tests. BMJ. 2001;323(7305):157-62. https://doi.org/10.1136/bmj.323.7305.157.

12. Huang $P$, Sun $Y$, Chen Y, Wang P, Shen Y. Clinical significance of EA-lgA antibody detection in Nasopharyngeal Carcinoma patients. J Fujian Med Coll. 1988;1:16-8.

13. Mai S, Zong Y, Zhang M, Zhong B, Lin S. Detection of Epstein-Barr virus DNA in plasma/serum: a useful serological indicator for diagnosis of nasopharyngeal carcinoma. Chin Med J. 2002;115(12):1895-7. https://doi. org/10.3760/j.issn:0366-6999.2002.12.031.

14. Cheng W, Cheng G, Cheng H, Luo R. Assessment of nasopharyngeal carcinoma risk by EB virus antibody profile. Chin J Oncol. 2002;24(06):45-7. https://doi.org/10.1038/sj.cr.7290128.

15. Zhang C, Zong Y, Huang B, Sun Y, Ye Y, Feng K, et al. Enhancing the effciency of epstein-barr viral serologic test in the diagnosis of nasopharyngeal carcinoma. Chin J Oncol. 2002;24(04):356-9. https://doi. org/10.3760/j.issn:0253-3766.2002.04.013.

16. GuY, Zhang C, Ng S, Zong Y. Study on Sero-Diagnosis of Nasopharyngeal carcinoma using a dual antibody test against recombinant EpsteinBarr Virus Antigens. Chin J Clin Cancer. 2003;22(09):903-6. https://doi. org/10.3969/j.issn.1000-467X.2003.09.002.

17. Chan KH, Gu YL, Ng F, Ng PS, Seto WH, Sham JS, et al. EBV specific antibody-based and DNA-based assays in serologic diagnosis of nasopharyngeal carcinoma. Int J Cancer. 2003;105(5):706-9. https://doi.org/10.1002/ ijc.11130.

18. Shao J, Li Y, Gao H, Wu Q, Cui N, Zhang L, et al. Comparison of plasma Epstein-Barr virus (EBV) DNA levels and serum EBV immunoglobulin A/ virus capsid antigen antibody titers in patients with nasopharyngeal carcinoma. Cancer. 2004;100(6):1162-70. https://doi.org/10.1002/cncr.20099.

19. Leung SF. Improved accuracy of detection of nasopharyngeal carcinoma by combined application of circulating Epstein-Barr virus DNA and anti-epstein-barr viral capsid antigen IgA Antibody. Clin Chem. 2004;50(2):339-45. https://doi.org/10.1373/clinchem.2003.022426.

20. Hu W, Zong Y, Li F. Comparison of six antibody assays detecting epstein-barr virus for serodiagnosis of nasopharyngeal carcinoma. Chin J Clin Oncol. 2006;33(14):795-8. https://doi.org/10.3969/j. issn. 1000-8179.2006.14.005.

21. Fachiroh J, Paramita DK, Hariwiyanto B, Harijadi A, Dahlia HL, Indrasari $\mathrm{SR}$, et al. Single-assay combination of epstein-barr virus (EBV) EBNA1and viral capsid antigen-p18-derived synthetic peptides for measuring anti-EBV immunoglobulin $\mathrm{G}(\mathrm{lgG})$ and $\lg A$ antibody levels in sera from nasopharyngeal carcinoma patients: options for field screening. J Clin Microbiol. 2006;44(4):1459-67. https://doi.org/10.1128/ JCM.44.4.1459-1467.2006.

22. Zhu W, Liang Y, Zhang Y, et al. Applying EBV Rta-lgG in diagnosis of nasopharyngeal carcinoma. Chin J of Oncol Prev Treat. 2009;1 (3):211-3. https://doi.org/10.3969/j.issn.1674-5671.2009.03.06.

23. Liang Y, Zong Y, Gu Y, Zhang Y, Feng Y, Liu Y, et al. Application of enzyme-linked immunosorbent assay to the serological diagnosis of nasopharyngeal carcinoma. J Pract Med. 2008;24(17):3055-8. https:// doi.org/10.3969/.issn.1006-5725.2008.17.063.

24. Sun J, Zheng A. Clinical significance of plasma EBV-DNA and VCA-IgA for nasopharyngeal carcinoma. J Modern Oncol. 2008;16(12):2086-7. https://doi.org/10.3969/j.issn.1672-4992.2008.12.016.

25. Chang K, Hsu C, Chang Y, Tsang N, Chen C, Lee T, et al. Complementary serum test of antibodies to Epstein-Barr virus nuclear antigen-1 and early antigen: a possible alternative for primary screening of nasopharyngeal carcinoma. Oral Oncol. 2008;44(8):784-92. https://doi. org/10.1016/j.oraloncology.2007.10.003.

26. Gu AD, Mo HY, Xie YB, et al. Evaluation of a multianalyte profiling assay and an enzyme-linked immunosorbent assay for serological examination of Epstein-Barr virus-specific antibody responses in diagnosis of nasopharyngeal carcinoma. Clin Vaccine Immunol. 2008;15(11):1684-8. https://doi.org/10.1128/CVI.00135-08.

27. Zheng Y, Cai Y, Cheng J, Qing Y. Evaluation of detection of Epstein.Barr virus Rta/lgG in nasopharyngeal carcinoma. Chinese J Exp Clini Virol. 2009;23(4):285-7. https://doi.org/10.3760/cma.j.i ssn.1003-9279.2009.04.015.
28. Luo Y, Ou G, Chi P, Liang Y, Liu Y, Huang M. Combined determination of Epstein-Barr virus-related antibodies and antigens for diagnosis of nasopharyngeal carcinoma. Chin J Clin Cancer. 2009;28(1):96-9. https ://doi.org/10.3321/j.issn:1000-467X.2009.01.019.

29. Jiang $\mathrm{S}$, Liu Q. Application of logistic regression in combination with mutiple diagnostic tests for auxiliary diagnosis of nasopharyngeal carcinoma. Chin J Clin Cancer. 2009;2(28):213-6. https://doi.org/10.3321/j. issn:1000-467X.2009.02.020.

30. Deng Z. Value of detection of serum EBNAI -IGA and EBVCA -IgA by ELISA in diagnosis of nasopharyngeal carcinoma. China Tropical Med. 2009;9(9):1718-97.

31. Kong P. The clinical value of the quantitative determination of EBV-DNA in blood serum and PBMC patients with nasopharyngeal carcinoma. J Shandong Med Coll. 2010;32(05):321-4. https://doi.org/10.14166/j.i ssn.1671-2420.2012.01.010

32. Sun J, Wang H, Xiao F, Liu Y. Clinical application of plasma cell free EBV-DNA serum CYFRA21-1 and VCA-IgA in patients with nasopharyngeal carcinoma. J Modern Oncol. 2010;18(10):1930-2. https://doi. org/10.3969/j.issn. 1672-4992.2010.10.17.

33. Liu Y, Huang Q, Liu W, Liu Q, Jia W, Chang E, et al. Establishment of VCA and EBNA1 IgA-based combination by enzyme-linked immunosorbent assay as preferred screening method for nasopharyngeal carcinoma: a two-stage design with a preliminary performance study and a mass screening in southern China. Int J Cancer. 2012;131(2):406-16. https:// doi.org/10.1002/ijc.26380.

34. Liu W, Du K. Clinical significance of plasma Epstein-Bar virus DNA concentration in the diagnosis and treatment of nasopharyngeal carcinoma. Hainan Med J. 2012;23(18):7-9. https://doi.org/10.3969/j. issn.1003-6350.2012.18.003.

35. Zhu H, He X. Significance of detecting plasma EBV-DNA and VCAIgA in patients with nasopharyngeal carcinoma. J Chinese Oncol. 2012;12(2):111-3.

36. Wang ZJ, Cao WJ, Chen F, Jian S, Tang L, Wang S. Analysis of antiEpstein-Barr virus antibody in patients with nasopharyngeal carcinoma in Shanghai. Chinese J Ophthalmol Otorhinolaryngol. 2012;12(1):406. https://doi.org/10.14166/j.issn.1671-2420.2012.01.010.

37. Ai P, Wang T, Zhang H, Wang Y, Song $C$, Zhang $L$, et al. Determination of antibodies directed at EBV proteins expressed in both latent and lytic cycles in nasopharyngeal carcinoma. Oral Oncol. 2013;49(4):326-31. https://doi.org/10.1016/j.oraloncology.2012.10.001.

38. Deng Z, Zhang Z. Relationship between EBVNAI-IgA and VCA-IgA antibodies with diagnosis and therapeutic effect of nasopharyngeal carcinoma. J Med Forum. 2011;32(19):108-14.

39. Li Z, Wong YL. Quantitative detection of EBV-DNA for diagnosis of nasopharyngeal carcinoma. China Modern Med. 2013;20(14):106-7. https:// doi.org/10.3969/j.issn.1674-4721.2013.14.052.

40. Li X, Chen Y, Zhen R, Pen W, Gao Y, Ye Q. The application value of EpsteinBarr virus Rta protein antibody lgG combined with two antibodies in the diagnosis and screening of nasopharyngeal carcinoma. Lab Med Clin. 2013;10(03):321-3. https://doi.org/10.3969/j.issn.1672-9455.2013.03.035.

41. Luo YL, Chen H, Peng SG, et al. Assessment of detection assays of Epstein-Barr viral Rta-IgG, VCA, IgA, EA-IgA and Epstein-Barr viral DNA at different clinical stages in the diagnosis of nasopharyngeal carcinoma. Natl Med J China. 2013;93(44):3516-9. https://doi.org/10.3760/cma.j.i ssn.0376-2491.2013.44.007.

42. Yan CE, Wang MJ, Jia DQ, et al. Diagnostic value of combined measurement of serum SA, EA-lgA, VCA-lgA and CgA levels in patients with nasopharyngeal carcinoma. Chinese J Med. 2013;48(10):27-8. https://doi. org/10.3969/j.issn.1008-1070.2013.10.010.

43. Tang GQ, Sa HF, Tang YZ. Detection of serum Epstein-Barr virus Rta-lgG applied to diagnosis of Nasopharyngeal carcinoma. Guangxi Med J. 2014;36(8):1083-5.https://doi.org/10.11675/j.issn.0253-4304.2014.08.20.

44. Cai Y, Li J, Lu A, Zheng Y, Zhong W, Wang W, et al. Diagnostic significance of combined detection of Epstein-Barr virus antibodies, VCA/IgA, EA/lgA, Rta/lgG and EBNA1/IgA for nasopharyngeal carcinoma. Asian Pac J Cancer Prev. 2014;15(5):2001-6. https://doi.org/10.7314/apjcp.2014.15.5.2001.

45. Peng YH, Xu YW, Huang LS, Zhai T, et al. Autoantibody signatures combined with Epstein-Barr virus capsid antigen-IgA as a biomarker panel for the detection of nasopharyngeal carcinoma. Cancer Prev Res. 2015;8(8):729-36. https://doi.org/10.1158/1940-6207.CAPR-14-0397. 
46. Xu Q, Zheng SH, Lin SX. Clinical value of Rta protein antibody lgG of EB virus in diagnosis for nasopharynx cancer. Int I Lab Med. 2015;36(17):2500-1. https://doi.org/10.3969/j.issn.1673-4130.2015.17.019.

47. Xia C, Zhu K, Zheng G. Expression of EBV antibody EA-IgA, Rta-lgG and VCA-IgA and SA in serum and the implication of combined assay in nasopharyngeal carcinoma diagnosis. Int J Clin Exp Pathol. 2015;12(8):16104-10.

48. Ye Q, Li X, Chen Y, Guo J. Diagnostic value of serological Epstein-Barr viral antibodies and Epstein-Barr viral DNA Assays in the management of nasopharyngeal carcinoma. Modern Oncol. 2016;19(24):3045-8. https:// doi.org/10.3969/j.issn.1672-4992.2016.19.012.

49. Li RC, Du Y, Zeng QY, et al. Epstein-Barr virus glycoprotein gH/gL antibodies complement IgA-viral capsid antigen for diagnosis of nasopharyngeal carcinoma. Oncotarget. 2016;7(13):16372-83. https://doi.org/10.18632/ oncotarget.7688.

50. Yu X, Ji M, Cheng W, Huang Y, Li F. Assessment of EBV antibodies and EBV-DNA in the diagnosis and stages of nasopharyngeal carcinoma. Chin J Clin Oncol. 2016;43(15):650-4. https://doi.org/10.3969/j. issn.1000-8179.2016.15.393.

51. Li Y, Wang K, Yin SK, Zheng HL, Min DL. Expression of Epstein-Barr virus antibodies EA-lgG, Rta-lgG, and VCA-lgA in nasopharyngeal carcinoma and their use in a combined diagnostic assay. Genet Mol Res. 2016. https ://doi.org/10.4238/gmr.15017368.

52. Zhao X, Zhang L, Quan C, et al. Clinical significance of EBV-BRLF1 gene and EBV-Rta/lgG antibody expression in nasopharyngeal carcinoma. Chin J Ophthalmol Otorhinolaryngol. 2016;16:243-7. https://doi.org/10.14166 /j.issn.1671-2420.2016.04.004.

53. Gu X, Li Y, Lv R, Sheng H. The correlation between serum homocysteine and EB virus three antibodies in nasopharyngeal carcinoma and the evaluation of its diagnosis performance. Chin J Health Lab Tec. 2016;26(02):231-3.

54. Guo J, Zhen Y, Chui Z, et al. Associations and interactions between EB virus infection and XRCC1 Arg399GIn polymorphism in nasopharyngeal carcinoma. Exp Lab Med. 2016;34(5):539-44. https://doi.org/10.3969/j. issn.1674-1129.2016.05.002

55. Gao R, Wang L, Liu Q, Zhang L, Ye Y, et al. Evaluation of seven recombinant VCA-IgA ELISA kits for the diagnosis of nasopharyngeal carcinoma in China: a case-control trial. BMJ Open. 2017;7(6):e013211. https://doi. org/10.1136/bmjopen-2016-013211.

56. Zhao M, Chen XH. Clinical value of serum EB virus gene, carcinoembryonic antigen and ferritin in diagnosis of nasopharyngeal carcinoma. Med Innovat China. 2018;15(23):134-7. https://doi.org/10.3969/j. issn.1674-4985.2018.23.035.

57. Yi XH, Lai HC, Liu JZ, Lin SC, et al. The combined interpretation schemes including VCA-lgA, EA-lgA and Rta-lgG in diagnosis of nasopharyngeal carcinoma. J Clin Otorhinolaryngol Head Neck Surgery. 2018;32(22):17404. https://doi.org/10.13201/j.issn.1001-1781.2018.22.014.

58. Zhang YN. The serum antibody Level changes of Rta-lgG/NCA-lgA and EA-IgA in nasopharyngeal carcinoma patients before and after radiation therapy. Univ South China. 2018;8:1-62.

59. Cao S, Simons MJ, Qian C. The prevalence and prevention of nasopharyngeal carcinoma in China. Chin J Clin Cancer. 2011;30(2):1 14-9. https://doi. org/10.5732/cjc.010.10377.

60. Puthavathana P, Kositanont U, Chongkolwatana C, Metheetrairut C, Chantarakul N, Nuntarakchaikul S, et al. Prevalence of IgA specific antibodies to Epstein-Barr virus capsid and early antigens in nasopharyngeal carcinoma. Asian Pac J Allergy Immunol. 1993;11(1):39-43. https://doi. org/10.1016/S0335-7457(05)80159-5.

61. Lam WKJ, Chan KCA, Lo YMD. Plasma Epstein-Barr virus DNA as an archetypal circulating tumor DNA marker. J Pathol. 2019;247(5):641-9. https:// doi.org/10.1002/path.5249.

62. Lo YM, Chan LY, Chan AT, et al. Quantitative and temporal correlation between circulating cell-free Epstein-Barr virus DNA and tumor recurrence in nasopharyngeal carcinoma. Cancer Res. 1999:59(21):5452-5.

63. Han $B L, X u X Y$, Zhang $C Z$, et al. Systematic review on Epstein-Barr Virus (EBV) DNA in diagnosis of nasopharyngeal carcinoma in Asian populations. Asian Pac J Cancer Prev. 2012;13(6):2577-81. https://doi. org/10.7314/APJCP.2012.13.6.2577.

64. Li S, Deng Y, Li X, et al. Diagnostic value of Epstein-Barr virus capsid antigen-IgA in nasopharyngeal carcinoma: a meta-analysis. Chin Med J. 2010;123(9):1201-5. https://doi.org/10.3760/cma.j.t ssn.0366-6999.2010.09.018.

65. Cui ZL, Lin YY, Chen YS, Zheng YH, Chen Y. BRLF1 transcription activator IgG targeting Epstein-Barr virus hallmarks promising diagnostic efficacy in identification of nasopharyngeal carcinoma: a meta-analysis study. Int J Clin Exp Pathol. 2017;10(2):1113-21.

66. Hanley JA, McNeil BJ. The meaning and use of the area under a receiver operating characteristic (ROC) curve. Radiology. 1982;143(1):29-36. https ://doi.org/10.1148/radiology.143.1.7063747.

67. Jones CM, Athanasiou T. Summary receiver operating characteristic curve analysis techniques in the evaluation of diagnostic tests. Ann Thorac Surg. 2005;79(1):16-20. https://doi.org/10.1016/j.athoracsur.2004.09.040.

68. Qu H, Huang Y, Zhao S, Zhou Y, Lv W. Prognostic value of Epstein-Barr virus DNA level for nasopharyngeal carcinoma: a meta-analysis of 8128 cases. Eur Arch Otorhinolaryngol. 2020;277(1):9-18. https://doi. org/10.1007/s00405-019-05699-9.

69. Agsalda-Garcia M, Shieh T, Souza R, et al. Raman-enhanced spectroscopy (RESpect) probe for childhood non-hodgkin lymphoma. SciMedicine Journal. 2020;2(1):1-7. https://doi.org/10.28991/SciMedJ-2020-0201-1.

70. King AD, Woo JKS, Ai QY, et al. Complementary roles of MRI and endoscopic examination in the early detection of nasopharyngeal carcinoma. Ann Oncol. 2019;30(6):977-82. https://doi.org/10.1093/annonc/mdz106.

71. Gomez AML, Santana PC, Mourao AP, et al. Dosimetry study in head and neck of anthropomorphic phantoms in computed tomography scans. Sci Med J. 2020;2(1):38-43. https://doi.org/10.28991/SciMedJ-2020-0201-6.

72. Abdelaal AM, Attalla EM, Elshemey WM. Estimation of out-of-field dose variation using markus ionization chamber detector. Sci Med J. 2020;2(1):8-15. https://doi.org/10.28991/SciMedJ-2020-0201-2.

73. Tang JW, Rohwäder E, Chu IMT, Tsang RKY, Steinhagen K, Yeung ACM, et al. Evaluation of Epstein-Barr virus antigen-based immunoassays for serological diagnosis of nasopharyngeal carcinoma. J Clin Virol. 2007;40(4):284-8. https://doi.org/10.1016/j.jcv.2007.09.006.

\section{Publisher's Note}

Springer Nature remains neutral with regard to jurisdictional claims in published maps and institutional affiliations.

Ready to submit your research? Choose BMC and benefit from:

- fast, convenient online submission

- thorough peer review by experienced researchers in your field

- rapid publication on acceptance

- support for research data, including large and complex data types

- gold Open Access which fosters wider collaboration and increased citations

- maximum visibility for your research: over 100M website views per year

At BMC, research is always in progress.

Learn more biomedcentral.com/submissions 